\title{
Una ficción propia. Notas sobre el nacimiento de la ficción contemporánea a partir de Fundido a blanco, de Oscar Muñoz, y La experiencia dramática, de Sergio Chejfec
}

A One-of-a-Kind Fiction. Notes on the Birth of Contemporary Fiction from Fundido a blanco, by Oscar Muñoz and La experiencia dramática, by Sergio Chejfec Uma ficção própria. Notas sobre o nascimento da ficção contemporânea a partir de Fundido a blanco (Fundido a branco), de Oscar Muñoz e La experiencia dramática (A experiência dramática), de Sergio Chejfec

\section{Luz Horne}

UNIVERSIDAD DE SAN ANDRÉS, BUENOS AIRES, ARGENTINA

Profesora de Literatura del Departamento de Humanidades de la Universidad de San Andrés. Obtuvo su doctorado en Literatura Brasileña e Hispanoamericana en Yale University, Estados Unidos. Ha sido profesora en Cornell University y Northwestern University. Ha publicado varios artículos sobre literatura hispanoamericana y brasileña en libros y revistas académicas. Autora de Literaturas reales. Transformaciones del realismo en la narrativa latinoamericana contemporánea (Beatriz Viterbo, 2011). Correo electrónico: lhorne@udesa.edu.ar

Artículo de reflexión

Documento accesible en línea desde la siguiente dirección: http://revistas.javeriana.edu.co 


\section{Resumen}

Este artículo toma dos obras

-Fundido a blanco, de Oscar Muñoz y La experiencia dramática, de Sergio

Chejfec- como un laboratorio para reflexionar sobre las transformaciones que sufre la categoría de ficción en el arte y la literatura contemporáneos. Si bien en estas obras se reflexiona sobre el ejercicio autobiográfico, en ellas se propone que la imagen y la palabra se despeguen de una temporalidad biográfica y cronológica para dar lugar a un recuerdo que sobrevive como un resto material, sensorial y afectivo. De este modo, se cancela la posibilidad de leer o mirar las obras en sus aspectos puramente testimoniales; o más bien se devela la trampa ficcional que allí se esconde. La urdimbre de la ficción, entonces, ya no se basa en una verosimilitud sino en la invención de un indicio o en la simulación de un documento.

Palabras clave: concepto de ficción; literatura e imagen; Sergio Chejfec; Oscar Muñoz

\section{Abstract}

This article takes two works - Fundido a blanco, by Oscar Muñoz and La experiencia dramática, by Sergio Chejfec - as a laboratory to reflect on the transformations that the fiction category undergoes in contemporary art and literature. Although these works reflect on the autobiographical practice, they propose image and word to be separated from a biographical and chronological temporality, leading to a memory surviving as a material, sensorial, and affective remainder. In this way, the possibility to read or look at the works in their merely testimonial aspect is cancelled; or rather, the fiction trap hidden there is revealed. Then, the scheme of fiction is no longer based on an authenticity, but on the invention of a hint or the simulation of document.

Keywords: concept of fiction; literature and image; Sergio Chejfec; Oscar Muñoz

\section{Resumo}

Este artigo pega duas obras -Fundido a blanco, de Oscar Muñoz e La experiencia dramática, de Sergio Chejfeccomo laboratório para refletir sobre as transformações que sofre a categoria de ficção na arte e literatura contemporâneas. Bem que nestas obras reflete-se sobre o exercício autobiográfico, nelas propõe-se que a imagem e a palavra se desapeguem de una temporalidade biográfica e cronológica para dar lugar a uma lembrança que sobrevive como resto material, sensorial afetivo. Deste jeito, cancela-se a possibilidade de ler ou assistir as obras nos seus aspetos puramente testemunhais; ou aliás, a armadilha ficcional que ali se esconde é desvendada. A urdidura da ficção, então, não é mais baseada em uma verossimilitude senão na invenção de um indício ou na simulação de um documento.

Palavras-chave: conceito de ficção; literatura e imagem; Sergio Chejfec; Oscar Muñoz

RECIBIDO: 25 DE OCTUBRE DE 2015. ACEPTADO: 20 DE NOVIEMBRE DE 2015. DISPONIBLE EN LÍNEA: 1 DE JULIO DE 2016

Cómo citar este artículo:

Horne, Luz. "Una ficción propia: notas sobre el nacimiento de la ficción contemporánea a partir de Fundido a blanco, de Oscar Muñoz, y La experiencia dramática, de Sergio Chejfec". Cuadernos de Literatura 20.40 (2016): 89-102. http://dx.doi.org/10.11144/Javeriana.cl20-40.fpnn 
FUNDIDO A BLANCO es una videoinstalación del fotógrafo colombiano Oscar Muñoz, de aproximadamente diez minutos de duración. Forma parte de su muestra Protografías, expuesta por primera vez en Cali, en 2010, y repetida en 2012 en el Museo de Arte Latinoamericano de Buenos Aires. Uno de los ejes de la exhibición en su conjunto giraba alrededor del autorretrato y de los modos de inclusión del yo dentro de la obra. Fundido a blanco no es una excepción. En un primer plano y a lo largo de todo el video, vemos al padre del fotógrafo, sentado, mirando a la cámara y en silencio. Detrás de él hay un fondo blanco con una ventana por la que entra una luz muy fuerte, un viento que produce un movimiento leve de las cortinas que están en el plano del fondo y un ruido apenas audible pero constante. Sobre ese fondo, hacia un costado, desplazado y fuera de cuadro, un retrato de la madre colgado en la pared mira al espectador y al propio Muñoz, quien - detrás de la cámara - conforma el tercer vértice de este retrato familiar y autobiográfico.

Más allá de las reminiscencias velazquianas, lo que llama la atención de este video subtitulado "Dos retratos", por la presencia de ambos padres, son dos cosas: la intensa luz y la ausencia de un relato explícito o de palabras. Se trata de una escena que podría ser de entrevista. Algo que ya hemos visto muchas veces antes: el hijo frente al padre, filmándolo, indagando sobre su historia familiar, con ansias de saber, de descubrir algo que lo ayude a revelar parte de su identidad. Sin embargo, el espectador se queda esperando algo que nunca llega. Durante los diez minutos de duración del video no pasa mucho más que lo visto desde el comienzo. En lugar del esperado diálogo entre el padre y el hijo, se escucha la respiración pausada del padre produciendo un efecto doble y contradictorio: reafirmando su vida y, simultáneamente, poniendo en un primer plano su cansancio, su vejez y la cercanía de su muerte. El hijo no pregunta y el padre calla. Por momentos su cabeza vacila, sus ojos pestañean: se duerme. El espectador no puede dejar de sentir una cierta incomodidad o impaciencia que necesariamente lo perturba, que produce una inquietud o una conmoción y, al mismo tiempo, una empatía. Uno imagina lo que sentirá el padre frente al hijo filmándolo sin preguntarle nada o lo que pensará el hijo mirando a su padre a través de la cámara: un exceso que no se dice, pero que se escucha como un ritmo respiratorio y se ve como una luz resplandeciente. Tanta es la luminosidad en la toma, que la percepción del personaje central - vestido de blanco y, por lo tanto, fundiéndose en el fondo blanco- se desdibuja en sus contornos. Pero, además de quitarle la nitidez al cuerpo del padre y de hacer como si se estuviera derritiendo bajo el efecto de la luz intensa del día, el brillo del sol produce - con sus reflejos- un constante ir y venir; un aparecer y desaparecer del retrato de la madre que se 
vislumbra en el fondo. Como si fuera una reminiscencia del fort- $d a$ freudiano, de una pulsión que se atraganta en el decir pero que se repite incansablemente y que siempre vuelve al mismo lugar. A través de la palabra ausente se subraya la presencia de un vacío, de un fuera de campo que deviene sonido constante y luz brillante; y que encandila al espectador en un ritmo incesante de ir y venir.

Según quisiera pensar aquí, Fundido a blanco ilustra de un modo muy nítido algunos de los problemas más interesantes que nos plantean el arte y la literatura contemporáneos. Problemas relacionados con el proceso de traducción de la memoria en imagen, con la condición misma de la imagen en su vínculo con el tiempo - con su preñez temporal-, con la inclusión del yo dentro de la obra, con el vínculo entre ficción y documentalidad y con la producción de afectos. En un iluminador ensayo en el que analiza la exhibición Protografías en su conjunto, Paola Cortes Rocca dice que en ella hay "un sujeto omnipresente en toda la muestra: el propio Oscar Muñoz" (33). En relación con esto, el video lleva un procedimiento al extremo, en el que me interesa indagar, pues en este se trabaja a partir de un vaciamiento de contenido o, más bien, a través de la introducción de un desfasaje entre una temporalidad biográfica y la temporalidad de la imagen, entre un posible relato cronológico de vida que nunca llega y una sensorialidad excesiva que es la que efectivamente recibimos como espectadores a través de una sola escena recortada y aislada de la vida entera. No se trata de una película, sino de una foto en movimiento. Es una escena que queda "en blanco", que no se llena con una historia particular, que se despega del relato psicológico: no hay recuerdos que contar, no hay novela familiar, no hay drama ni tampoco trama. Es simultáneamente algo íntimo e impersonal que resulta en la exposición de una afectividad que "se vuelve independiente de aquel que la vivencia" (Deleuze y Guattari 170). Así, aun cuando hay algo evidentemente autobiográfico, los recuerdos no se traducen en imagen o en palabra de manera nítida y diacrónica, pegados a la experiencia que les da origen, sino que más bien se exponen de un modo intermitente: como un efecto del viento, de la respiración y del reflejo del sol, es decir, con una sensorialidad exacerbada que subraya un vínculo entre memoria y corporalidad. Por momentos, la cortina cubre completamente el rostro del padre y la pantalla entera queda en blanco. Sin embargo, a través de la tela adivinamos su silueta, que sobrevive como una presencia fantasmal. Son momentos fugaces que agujerean con un brillo encandilante la autonomía de la obra - después de todo es el propio padre de Muñoz el que tenemos enfrente-, pero que mantienen una distancia que impide que pueda considerarse como un documento o como un testimonio. Quisiera proponer aquí que el modo en el cual se reflexiona sobre la transformación de la memoria en imagen en este video 
puede servir como base para pensar en el proceso de construcción ficcional autobiográfica en cierto tipo de arte y literatura contemporáneos.

\section{La vida sin interferencias: de la experiencia a la escena dramática}

La experiencia dramática, de Sergio Chejfec, resulta un texto apropiado para pensar en diálogo con el video de Muñoz. A primera vista pareciera no funcionar como un ejemplo paralelo, pues no es una novela directamente autobiográfica y está narrada de un modo casi clásico en tercera persona. Sin embargo, el horizonte de problemas que surgen de su lectura es similar. Como en casi todas las novelas de Chejfec, en sus páginas no hay una trama sólida, sino que simplemente seguimos a un hombre, Félix, y a una mujer, Rose, que se encuentran regularmente a conversar y a caminar por la ciudad. En estos recorridos se ponen en paralelo dos situaciones. La primera tiene que ver con el registro cartográfico de la ciudad, con el modo de funcionamiento y la capacidad de archivo de Google Maps. El recorrido de Félix y Rose por la ciudad se narra a través de una lógica que podríamos llamar digital: el texto acompaña el paseo de sus protagonistas acercándose o haciendo zoom en diferentes puntos, se va metiendo en el detalle de diferentes escenas que se siguen por algunas páginas, se desarrollan brevemente y luego se abandonan hasta encontrar la siguiente. Pero esta lógica digital de los recorridos urbanos también se asocia con otro tipo de lógica, una "teatral", pues se va plasmando la idea de la ciudad como un escenario y del deambular en ella como improvisación y actuación. Y es justamente con el teatro que se vincula la segunda situación sobre la cual reflexiona la novela y de la cual surge su título. Se trata de un ejercicio que le proponen a Rose, que es actriz, en su clase de actuación y que consiste en lo siguiente: "El ejercicio para el taller de teatro consiste en revivir situaciones dramáticas. Uno debe elegir, y escenificar, la experiencia cierta más dramática de su vida" (34, cursivas de la autora).

Rose y Félix recorren la ciudad conversando sobre cuáles podrían ser las experiencias dramáticas de la gente que conocen; sobre qué podría calificar y qué no como experiencia dramática y, sobre todo - lo que me interesa particularmente- acerca de cómo sería el proceso de traducción de una experiencia a una escena dramática: "Ella considera sin embargo que no es suficiente con haber pasado por la experiencia dramática, [sino que se] debía encontrar la escena dramática [...] La escena expuesta y en cierto modo fabricada podría no ser verdad, en el sentido de pertenecer a una cadena de hechos no verificables en la realidad" (99, cursivas de la autora).

La distinción entre una experiencia dramática y una escena que la pueda ilustrar es clave, porque es la que establece el nacimiento de la ficción. En algún 
sentido esto parece obvio, pero lo singular de este proceso, tal como es pensado aquí, está en que la traducción de la experiencia a la escena o el pasaje de un hecho referido al pasado al momento presente se entiende en paralelo a la lógica del funcionamiento de los mapas en línea. De este modo, los recorridos de Félix y Rose por la ciudad y su constante pasaje a un mapa virtual no hacen más que ir reproduciendo este otro pasaje: el de la experiencia a la escena o a la ficción.

En un ensayo llamado "Lo que viene después", Chejfec asocia esta lógica de los mapas virtuales con la simulación y la propone como un registro propio de la literatura contemporánea, opuesto al de la representación: "La literatura ya no, o no solamente, como estrategia de representación sino como ámbito de simulación, al modo de las opciones digitales presentes en los mapas en línea, o directamente al modo de los juegos" (8). Me interesa entonces pensar estas dos narraciones, Fundido a blanco y La experiencia dramática, como sitios en los cuales se despliega un modo singular de construcción ficcional subjetiva propio de la literatura y del arte contemporáneos, que podría ser entendido como simulación - tal como propone Chejfec-; pero también - siempre fuera de una lógica representativa- como síntoma o como supervivencia de un recuerdo en forma de resto sensorial, intermitente y afectivo. Según esta estructura, si bien se mantiene un residuo experiencial (el ejercicio de la clase de teatro exige que la experiencia sea "cierta"; el video es sobre el padre y la madre del propio Muñoz), en el pasaje al texto, a la imagen o a la "escena" se cancela la posibilidad de leer o mirar la obra en su faz puramente documental o testimonial; o - más bien - se devela la trampa ficcional que esconde lo documental y se nos brinda un indicio ficcional o una simulación.

En este proceso, el desfasaje entre una temporalidad biográfica o cronológica y la temporalidad que la obra nos brinda es crucial. Así como en Fundido a blanco no se cuenta una historia, en la novela también nos quedamos con una estructura en cierto sentido vacía. Hay una reflexión acerca de cómo se debería contar una historia personal e íntima, pero no leemos - propiamente hablandoninguna historia concreta o completa. En La experiencia dramática no hay, a pesar de la promesa del título, ningún drama: solo alusiones, apuntes o notas sobre ciertas experiencias que podrían llegar a devenir escenas. Cada una de estas vidas a las que las experiencias pertenecen se nos presenta a través de trozos sueltos, de retazos o jirones superpuestos, fuera de cualquier cronología diacrónica. ${ }^{1}$ Esta intermitencia con la que se revela la experiencia se pone en paralelo

1 La idea misma de elegir una única experiencia clave que sea "la más dramática" de toda la vida para mostrar con eso algo del propio drama de una vida entera implica una condensación de diferentes momentos, de diferentes temporalidades en una sola. 
con ciertas situaciones que viven Félix y Rose en sus recorridos por la ciudad. El flujo de tráfico, por ejemplo, se manifiesta simulando la forma en que se revelan los recuerdos del pasado:

[...] el pasado es un libreto que se revela con intermitencias, según picos y caídas $-o$ lagunas - de fidelidad [...] Rose considera que el pasado se sirve de intervalos para manifestarse, igual a esos flujos regulares de tránsito gobernados por los semáforos, como los de la avenida que acaban de dejar, y que sobre todo provee, el pasado, de márgenes de manifestación y descansos. (Chejfec, La experiencia ${ }_{17}$ )

Tanto en el video como en la novela los minutos transcurren, las páginas se suceden y, sin embargo, como espectadores o lectores percibimos que hay un cierto tartamudeo que no termina de definirse o que lo hace a través de intermitencias. Se produce entonces un desapego de la historia efectiva y se va construyendo una suerte de carcasa o "matriz vacía". ${ }^{2}$ Ahora bien, si por un lado este vacío señala la distancia con respecto a una temporalidad puramente biográfica $-\mathrm{y}$, por lo tanto, diferencia la obra de un testimonio o un documento-; por otro, cuestiona el estatus ficcional de estas narraciones, pues no propone ningún relato alternativo al biográfico: no inventa. No hay una trama que suplante el relato de vida, no hay una épica o una intriga, sino que se nos presenta algo "cierto" pero como una suspensión, una intermitencia o un blanco. La ficción adquiere - entonces - ciertas características particulares, ya que toma la forma

2 En una entrevista de hace algunos años, Sergio Chejfec menciona como un rasgo propio de la literatura contemporánea la falta de necesidad de definirse a sí misma como literatura a través de una épica, de una trama sólida o de una estructura de acción. Según esta inflexión, el viaje, por ejemplo, surge como un pretexto para construir obras que agrupan temas heterogéneos o para la reflexión pero no por presentar una estructura de acción. Así como el viaje - dice Chejfec - cualquier estructura que brinde una "matriz vacía" podría servir como una excusa para escribir una obra literaria: "El viaje, si quiere ser representado por la literatura, se ha convertido en una especie de murmullo, una reflexión alrededor de los detalles y las variaciones del mundo. Precisamente, eso hace que viajar no sea necesario, que se pueda considerar un viaje como una vuelta a la manzana. El viaje se ha transformado, como otro tipo de relato, en una especie de matriz vacía y, por lo mismo, sumamente rica. Se lo puede tomar como una excusa perfecta para hablar de muchas cosas al mismo tiempo. Eso es lo bueno que tiene, creo, la literatura contemporánea. Que todo es una excusa para ella" (Hounie s. p.; cursivas de la autora). Por supuesto, este rasgo de deflación de la trama, o de quiebre de una estructura de ordenamiento interno de la ficción a partir de la acción no sería - si seguimos a Rancièrealgo nuevo, sino un rasgo propio de la ficción moderna que surge con el realismo del siglo XIX. Sería en este momento cuando se quiebra con el orden representativo a través de la ruptura de su principio fundante: la jerarquía de la acción (Rancière, El hilo 20). 
de construcción verosímil (enredo, épica, drama o intriga), sino que se parece más bien a un documento visto a través de un filtro, a la silueta de un padre detrás de una cortina, a la imagen de una madre que de tanto iluminarse se vuelve a apagar, o a un relato cierto pero que, al ser actuado, se desplaza.

En otras obras de Chejfec, también aparece algo de esta preocupación por ubicar al texto dentro de un registro asociado al de la crónica personal, autobiográfica o íntima, pero manteniendo - al mismo tiempo- una ambivalencia en cuanto a su estatuto ficcional (y esto es así aunque sea por el hecho de que son textos que se editan bajo el rubro de "novelas" o "cuentos"). Es decir, en muchos de sus textos hay un anclaje documental que, sin embargo, se ficcionaliza, se simula o se "novela" - parafraseando uno de sus cuentos incluidos en Modo linterna titulado "Novelista documental" -, sin por eso perder algo de la inmediatez que lo relaciona con la experiencia. La trama de dicho cuento gira alrededor de este problema: un escritor acude a una suerte de congreso de escritores de novelas y de críticos literarios especializados en novelas que se realiza en un hotel en los Andes venezolanos. Allí se encuentra con una jaula de guacamayas cuyos sonidos lo van a obsesionar por el resto de la estadía. El escritor desea sacarse una foto junto a las guacamayas pero no lo logra. ${ }^{3}$ Las aves tienen una presencia esquiva que la foto no logra capturar y que tampoco la palabra logra atrapar, pues el sonido que emiten toca el registro de lo inenarrable y sus miradas el de lo intolerable: "No soy capaz de asignarle un nombre concreto a ese sonido"; "Ni por lo menos una fórmula descriptiva"; "Ninguna palabra resultaría efectiva, aún la más precisa, porque esa palabra debería referir también al aire, a los aromas, a la brisa y al paisaje en general" (Chejfec, Modo 97); "sencillamente la mirada de un ave no se tolera" (102).

Sin embargo, esta imposibilidad de nombrar el sonido de las aves, de mirarlas a los ojos o de capturar su imagen a través de la foto, se constituye como condición de posibilidad de la literatura; es aquello alrededor de lo cual el cuento mismo gira y, a partir de lo cual - aun sin nombrarlo ni registrarlo a través de la foto- se puede escribir. Hay algo en la voz de las guacamayas que desafía una clasificación simbólica: no puede definirse enteramente como un sonido animal (pues se trata de un lenguaje), pero tampoco como un sonido humano (pues se trata de un lenguaje que carece de ley, que carece de sentido). ${ }^{4}$ Este matiz inclasificable

3 "Durante los cinco días que duró el simposio no logré sacarme una sola foto con las guacamayas" (Chejfec, Modo 101).

4 "Suenan como chillidos, o igual a parodias de voz humana. Las exclamaciones de las guacamayas se alternan como si se tratara de temas de conversación habitual, y por eso actualizados con rapidez"(Chejfec, Modo 97); "Mientras tanto las guacamayas hablan en cualquier momento, sin descubrir algún ritmo fijo que regule las pausas" (105). 
e intolerable es el que resurge como un rasgo sensorial que no puede traducirse a la palabra o a la imagen - "esa palabra debería referir también al aire, a los aromas, a la brisa y al paisaje en general" (Modo 97) -, pero que de todos modos la literatura (este cuento que nosotros estamos leyendo) rodea incesantemente en su aspiración narrativa.

El escritor habla de su deseo de establecer algún tipo de comunicación con estas aves y - sin dejar de marcar su imposibilidad - lo compara con el deseo de transmitir algo de su propia experiencia a través de la literatura: "No es precisamente un deseo de hablar con los animales, sino la creencia de que me podré comunicar con ellos y que de esa forma algún matiz de mi experiencia o de mi sensibilidad será transmisible [...]; incluso he llegado a escribir novelas por el solo hecho de precisar ese tipo de trances" (104). Y es justamente en relación con este deseo de transmitir algo de la propia experiencia que aparece la necesidad de la foto, de la documentación de la experiencia para, a partir de esto, poder escribirla:

Le explico que soy novelista, como todos los demás, y que preciso las fotos para documentar que es cierto lo que escribo; que mi principal temor es encontrar a alguien que me pida cuentas, y después ante mi silencio me acuse de inventar todo. Le explico también que hasta a mí me llama la atención este miedo, porque en realidad nunca me propuse escribir la vedad, al contrario, siempre desprecié las novelas basadas en los hechos reales. Pero de un tiempo a esta parte, no sé si la realidad a secas, en todo caso el documento acerca de los hechos verdaderos, es lo único que me salva de una cierta sensación de disolución. La novela, le digo, puede ser ficción, leyenda o realidad, pero siempre debe estar documentada. Sin documento no hay novela, y yo preciso esta foto con las guacamayas para poder escribir sobre ellas y yo, porque de lo contrario cualquier cosa que ponga carecerá de profundidad; no dejará estela. (106 y 107)

Es decir, esta necesidad de que la ficción nazca, no como pura invención ni tampoco basada en la realidad "a secas", sino del documento, nos hace pensar en el tipo de literatura que Chejfec asocia en el ensayo antes citado con el modo de funcionamiento de los mapas digitales y que desafía la representación al basarse en la simulación. Tal como dice en aquel ensayo, la simulación no funciona como la representación en la medida en que "propone un vínculo directo y nunca desviado con el mundo que viene a simular, o imitar" (Chejfec, "Lo que viene" 7) y, por lo tanto, brinda a la literatura un "soporte testimonial" (8).

Este tipo de literatura representa, según se lee en estos textos, una novedad o, al menos, un rasgo que identifica la literatura contemporánea y la diferencia de 
cierta literatura que se calificará como "normal", en la que la ficción no nace de este soporte testimonial, sino que más bien se basa en la construcción de una verosimilitud. En otro de los cuentos de Modo linterna llamado "El testigo", un personaje que lee un epistolario de Cortázar menciona una inclinación reciente por "curiosear en historias que no le incumben" (Chejfec, Modo 123), y a pesar de que considera este interés pasajero o erróneo, "el hecho es que los libros llamados normales han dejado de motivarlo desde hace tiempo. Ahora quiere libros donde la vida se muestre sin interferencias" (123, cursivas de la autora). Como si en estas historias en las que se cuentan relatos "ciertos" - como las experiencias dramáticas requeridas en el ejercicio teatral o como en el video del padre de Muñoz - radicara algo de la particularidad o el interés de la literatura y el arte contemporáneos.

\section{La densidad del recuerdo: una luciérnaga, un brillo en la oscuridad}

Para entender este modo de concebir la categoría de ficción resulta útil remitirse a ciertas formulaciones teóricas sobre la fotografía y sobre el cine documental. En un ensayo llamado "Ficciones documentales", el fotógrafo catalán Joan Fontcuberta deconstruye allí lo que califica como el "discurso hegemónico de la modernidad fotográfica", según el cual la esencia de la fotografía residiría en su capacidad de significación indicial y en su "voluntad de testimonio" (104). Según Fontcuberta, a pesar de que a lo largo de la historia de la fotografía ha prevalecido una intención descriptiva, esta misma intención se ha valido, en muchas ocasiones, de lo que él califica como una "trampa", ya que involucra la urdimbre de una ficción. A través del análisis de uno de los primeros daguerrotipos conocidos -la vista del Boulevard du Temple (fechado en 1838) - y de una imagen de Hippolyte Bayard de 1840 en el que el autor de la foto se retrata a sí mismo simulando haberse suicidado, Fontcuberta descubre - "en el mismo nacimiento de la fotografía" (104) - la trampa que cuestiona, mientras que instituye, el estatuto de la foto como documento. La imagen de Daguerre es conocida, pero detengámonos en ella unos instantes. Se trata de una imagen doble: dos tomas efectuadas en el mismo día. En una de ellas se ve el boulevard completamente vacío en un horario en el que debería estar lleno de gente. Esta incompatibilidad se debe a que el tiempo de exposición que requería la obtención de la imagen en ese entonces no permitía captar ningún objeto en movimiento. Para esto Daguerre busca una solución - que se ve en la segunda toma- que es la de utilizar actores: un limpiabotas con su cliente sobre la vereda. De esta manera, engañando al espectador a través de una actuación, consigue una imagen más fiel a la realidad, pero para lograrlo precisa de una intervención ficcional, de una simulación. Esto produce 
un tipo particular de ficción, dice Fontcuberta, que "no es que se oponga a lo verdadero, sino que se opone tanto a lo verdadero como a lo falso (entendido lo falso como error o mentira). Tampoco se opone al discurso referencial sino que coloca al referente entre paréntesis" (109, cursivas de la autora).

Lo que me interesa particularmente de este tipo de construcción ficcional - para pensarlo en relación con las obras que me conciernen- es que en este caso se simula un documento y que la urdimbre de la ficción conlleva una actuación teatral, pero no necesariamente un relato alternativo. Es decir, se inventa ese referente que no se ve. Hay un resto experiencial que no se traduce en imagen; pero que se repone a través de la ficción y que queda, por lo tanto, entre paréntesis o suspendido en cuanto referente. En relación con esto mismo, en un ensayo en el que analiza un filme de Chris Marker,Jacques Rancière propone que en el trabajo que realiza el cine documental como género se puede ver cómo la categoría de ficción se reduce a "su esencia":

Le film documentaire peut donc isoler le tràvail artistique de la fiction en le dissocient de ce a quoi on l'assimile volontiers: la production imaginaire des vraisemblances et des effets de réel. Il peut le ramener à son essence: une manière de découper une histoire en séquences ou de montrer des plans en histoire, de joindre et de disjoindre des voix et des corps, des sons et des images, d'etirer ou de resserrer des temps. (La fable 203) ${ }^{5}$

Es decir, la disociación del concepto de ficción de la construcción de una verosimilitud - cuya correspondencia pertenece, según Rancière, a una poética clásica - nos lleva a pensarlo como aquello que produce un cambio en el modo de presentación sensible y que, por lo tanto, permite ver lo mismo de un modo diferente. En otros ensayos en los que vuelve sobre este asunto, Rancière insiste en que el trabajo de la ficción "no consiste en contar historias" (Rancière, Espectador 102), y en que su definición no debería basarse en la oposición entre "la realidad y sus apariencias" (102), sino más bien en la posibilidad de generar disenso, de construir otras formas de dar sentido: "un paisaje inédito de lo visible" (Rancière, Espectador 103).

"El cine documental puede entonces aislar el trabajo artístico de la ficción al disociarlo de aquello a lo que lo uno lo asimila gustosamente: a la producción imaginaria de verosimilitudes y de efectos de real. El cine documental puede llevar así el trabajo de la ficción a su esencia: una manera de recortar una historia en secuencias o de mostrar los planos en una historia, de unir y separar las voces y los cuerpos, los sonidos y las imágenes, de estirar o de ceñir los tiempos" (traducción de la autora). 
Sería equivocado leer en la distancia con respecto a una temporalidad biográfica un puro procedimiento formal y una defensa de la autonomía, pues allí, en este vacío que vuelve como exceso sensorial, deberíamos hallar el impacto afectivo, crítico y hasta político que estas obras procuran en la medida en que ahí se genera un sentido nuevo para aquello que ya estaba; allí se descubre una reminiscencia como si fuera una novedad. En La experiencia dramática, nuevamente es el flujo del tránsito el que sirve como excusa para hablar de modo oblicuo del interés que puede tener este vacío en la literatura: "Cuando el tránsito cesa la avenida se vacía hasta la próxima ráfaga. Vuelve entonces un silencio provisorio, hecho de espera. Durante esos lapsos sin actividad [...] la escenografía se mantiene igual $[. .$.$] como si según la lógica de la avenida, cuando no pasa nada es que$ vale la pena mirar" (Chejfec, Experiencia 14; cursivas de la autora).

Es decir, vale la pena mirar cuando nada ocurre, porque esta misma promesa de relato que no llega deja la marca de su ausencia en forma de registro corporal o sensorial, que llega como una ráfaga; tal como aquello que, sin decirse o sin recordarse, igual se revela. Como la respiración agitada del padre, la luminosidad encandilante y la intermitente aparición de la figura de la madre en Fundido a blanco. Como esa presencia fantasmal del padre en la cortina, impronta de su presencia real e impronta también de su ausencia efectiva. Son todos efectos que parecen traducciones de una reflexión de Rose en La experiencia dramática:

Se pone a pensar y el punto es que esos hechos del pasado, aunque vigentes en la memoria, han perdido intensidad y ahora tienen una presencia demasiado débil, como si la trama que los ha justificado, y luego sostenido, hubiese perdido nitidez [...] Como si la densidad del recuerdo radicara sobre todo en lo físico y lo demás se perdiera luego. (Chejfec, Experiencia 42 y 43 )

Es decir, despegarse de la trama biográfica que sostiene y justifica los recuerdos no implica no recordar, sino exponer los recuerdos en su densidad física, sensorial, corporal y afectiva. Hacia el final de la novela, cuando ya han conversado sobre las experiencias de diferentes personas, Félix espera que Rose le pregunte por su propia experiencia dramática; pero esta pregunta nunca llega y en su no llegar deja como marca corporal un nudo en la garganta. Se trata de un silencio o un blanco que, como en el video de Muñoz, deja una silueta:

[...] en ocasiones se producen momentos de vacilación. No son más que episodios fugaces, aunque se ponen en evidencia de manera notoria, con la fuerza de un brillo en la oscuridad. Lapsos muy breves, suficientes de todos modos para hacer ver que el silencio está escondido [ ... y que] sería como una cita, la prueba de otra cosa, a veces oculta. (Chejfec, Experiencia 34; cursivas de la autora) 
En Supervivencia de las luciérnagas, George Didi-Huberman retoma una metáfora que Pasolini había utilizado para referirse a ciertos momentos fugaces de amistad, felicidad y deseo ligados a un deseo artístico y a una resistencia frente al fascismo: las luciérnagas que danzan en la noche y se iluminan de un modo intermitente con un deseo de formar comunidad (55). Pero en los años setenta, Pasolini sentencia la muerte de las luciérnagas frente a lo que él considera una forma cultural en la que ya no hay espacio para estos resplandores. La mirada apocalíptica de Pasolini en su declaración de la muerte de las luciérnagas — sostiene Didi-Huberman - "es justamente dar crédito a lo que la máquina [totalitaria] nos quiere hacer creer. [...] es estar convencidos de que la máquina cumple su trabajo sin resto ni resistencia. Es no ver el espacio - aunque este sea intersticial, intermitente, nómade, situado en lo improbable-de las aperturas, de los posibles, de aquello que surge a pesar de todo" (Didi-Huberman 42).

Podríamos pensar entonces que en estas obras la ficción nace como si fuera una luciérnaga, como un resto que queda cuando la trama ha perdido nitidez. Si adonde vale la pena mirar es a ese sitio donde "no pasa nada", esto es así porque la imagen o la palabra se han despegado de una temporalidad biográfica y cronológica para dar lugar al recuerdo que sobrevive como un resto material, físico, sensorial: un brillo en la oscuridad, una respiración, un viento fuerte, una silueta, un nudo en la garganta. Se descubre entonces un nuevo sentido para aquello que parecía no decirnos nada nuevo y en este gesto se realiza una operación crítica. Se abre el campo para aquel sitio en el que - como ocurría con las luciérnagas de Pasolini- lo político encarna en los cuerpos. Son efectos que actúan, simulan o escenifican - como en la fotografía de Daguerre - un recuerdo o una experiencia, pero dejando el referente entre paréntesis, aludiendo a la verdad de otro modo; de un modo oblicuo, ficcional o tal vez — como querría Chejfec-, digital.

\section{Obras citadas}

Chejfec, Sergio. La experiencia dramática. Buenos Aires: Alfaguara, 2012. Impreso.

Chejfec, Sergio. "Lo que viene después". Documento procedente del

Seminario-Encuentro Literatura y Después. Reflexiones sobre el Futuro de

la Literatura Después del Libro", Sevilla, 17-19 de abril de 2012. Web.

Chejfec, Sergio. Modo linterna. Buenos Aires: Entropía, 2013. Impreso.

Cortés Rocca, Paola. "La condición de las imágenes".

Otra Parte 28 (2013): 32-38. Impreso.

Deleuze, Gilles y Felix Guattari. ¿Qué es la filosofía?

Barcelona: Anagrama, 1991. Impreso. 
Didi-Huberman, George. Supervivencia de las luciérnagas.

Madrid: Abada, 2012. Impreso.

Fontcuberta,Jean. "Ficciones documentales". La cámara de Pandora: la fotografía después de la fotografía. Barcelona: Gustavo Gili, 2010. Impreso.

Houni, Analía. "Noticias de un narrador cavilante: entrevista con Sergio Chejfec". Diario Perfil, 17 de junio de 2007. Web. (20/05/2014).

Rancière, Jacques. El espectador emancipado. Buenos Aires: Manantial, 2010. Impreso.

Rancière, Jacques. El hilo perdido: ensayos sobre la ficción moderna. Buenos Aires: Manantial, 2015. Impreso.

Rancière, Jacques. La fable cinématographique. Paris: Le Seuil, 2001. Impreso. 